\title{
Myrtia, $\mathrm{n}^{\circ} 36$ (2021), 143-157
}

Los Cynegetica de pseudo-Opiano, ¿poema incompleto?

[The Cynegetica of pseudo-Oppian, incomplete poem?]

\author{
Sebastián Martínez García ${ }^{1}$ \\ Institut Can Vilumara (L'Hospitalet de Llobregat)
}

Resumen:

Abstract:

Palabras clave:

Keywords:

Recepción:

En las primeras ediciones y estudios consagrados a los Cynegetica de pseudo-Opiano se argumentaba que el poema estaba incompleto; esta opinión se basaba principalmente en la promesa incumplida de III 404-6 y en la falta de un epílogo. Dando por válidas esas razones, el presente artículo estudia, en primer lugar, el contenido de los libros II y III, en los cuales se observan numerosos indicios de que el poeta conocía muchos más datos sobre la caza que los expuestos en el libro IV. En segundo lugar, estas páginas prestan atención al marcado contraste que se aprecia entre el esmerado proemio del libro IV y su abrupto final. Ambos aspectos, que anteriormente no habían sido apenas tenidos en cuenta, permiten completar la argumentación a favor del estado inacabado de los Cynegetica.

From the first editions and studies about the Cynegetica of pseudo-Oppian it has been argued that the poem was incomplete; it was based on the broken promise of III 404-6 and on the lack of an epilogue. Considering these reasons as valid, this article first studies the content of the books II and III, in which it is possible to find many indications that the author knew much more about the theme of the book IV (the description of hunting) than he revealed. Next, we pay attention to the contrast between the careful proem of the book IV and its abrupt ending. Both aspects that have been scarcely considered before enable to show the shortcoming of the book IV.

Opiano de Apamea, pseudo-Opiano, Cynegetica, caza, animales

Oppian of Apamea, pseudo-Oppian, Cynegetica, hunting, animals

$01 / 09 / 2020$

Aceptación: $\quad 30 / 01 / 2021$

A propósito de los Cynegetica, poema didáctico griego que fue escrito a comienzos del siglo III de nuestra era por un individuo natural de Apamea, conocido tradicionalmente con el nombre de $\mathrm{Opiano}^{2}$, se ha afirmado con alguna frecuencia que no es una obra completa, sino que falta alguna parte, más o menos extensa, del final. En nuestra opinión, el estudio de la estructura, contenido e interrelación de las partes del poema puede aportar indicios valiosos para reconsiderar la cuestión.

En el libro I los Cynegetica ${ }^{3}$ se ocupan de los elementos necesarios para practicar la caza: las horas del día, los instrumentos, los caballos y los perros, entre otros. El libro II describe principalmente la naturaleza y carácter de los animales cornúpetas, mientras que el libro III caracteriza a los depredadores. Finalmente, el libro IV relata la captura de algunos animales.

\section{Breve historia de la cuestión}

Las dudas sobre el estado de conservación de los Cynegetica comenzaron ya desde las primeras ediciones modernas, cuyos autores se fijaron principalmente en dos aspectos: la promesa incumplida de III 404-6 y la falta de un epílogo que señalara el final del poema. Nos ocuparemos detenidamente de ambos argumentos más adelante, ya que antes parece conveniente examinar las opiniones de la crítica.

El primer estudioso que hizo mención del posible estado incompleto del poema fue $\mathrm{J}$.

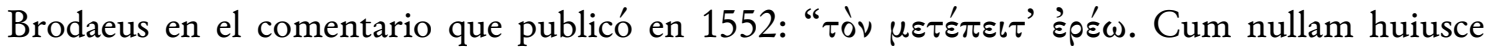

${ }^{1}$ Dirección para correspondencia: Sebastián Martínez García, Institut Can Vilumara. Josep Tarradellas, 153. 08901-L’Hospitalet de Llobregat (Barcelona). España. Correo electrónico: smartin4@xtec.cat

El autor quiere manifestar su agradecimiento al Dr. Tomás Silva Sánchez, profesor de la Universidad de Cádiz, cuyas aportaciones han contribuido a mejorar estas páginas.

2 Sobre la identidad del poeta, cf. R. Keydell, 1939, c. 698-700; A. W. Mair, 1928, pp. xiii-xxiii; S. Martínez T. Silva, 2003. Para las biografías bizantinas, cf. P. Hamblenne, 1968; S. Martínez, 2003.

${ }^{3}$ En general, para el contenido y estructura del poema, cf. R. Keydell, 1939, c. 704-6; T. Silva Sánchez, 1998, pp. 326-7. 
technae mentionem faciat Oppianus, multa libro quarto desiderari pro certo habemus" ${ }^{4}$. Según el turonense, falta una parte considerable del libro IV, dado que Opiano no vuelve sobre la técnica cinegética aludida en III 406. Tres años después, apareció la traducción latina con comentario de J. Bodinus, quien al final del texto en latín escribió "Desideratur liber quintus" 5 y que en la anotación correspondiente decía a propósito de dicho verso: "Epécu. ex eo loco

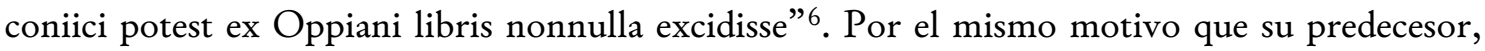
Bodinus postuló la pérdida de un quinto libro.

Por su parte, C. Rittershusius, refiriéndose también a III $406^{7}$, desarrollaba más extensamente el argumento:

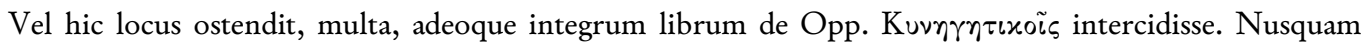
enim in his quidem qui ad nos pervenerunt, id quod hic pollicetur, praestat: quod et Brodaeum atque Bodinum admonuisse video. Huc adde alterum argumentum ex Epilogo $\tau \tilde{\omega} \nu{ }^{\circ} A \lambda \iota \varepsilon \cup \tau \iota x \tilde{\omega} \nu$ : et testimonium

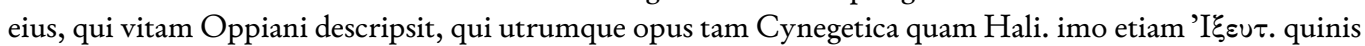
libris constitisse ait: cui potius fidem habendam existimo, quam Suidae. Accedat et hoc, quod numerus versuum libri quarti non est par reliquorum librorum numero. Vnde colligere facile est, aliqua interiisse. Solent enim auctores plerunque ita partiri libros, ut mole et prolixitate sint inter se pares.

Como hemos podido leer, además de hacerse eco de las opiniones de sus dos predecesores (falta una buena parte del poema o un libro entero), Rittershusius aportó alguna novedad: los Cynegetica carecen de un epílogo como los Halieutica, el libro IV es notablemente más breve que los anteriores o cierta Vita Oppiani asignaba cinco libros a cada una de las obras atribuidas a Opiano.

Estas opiniones fueron retomadas por otros estudiosos, como J. G. Schneider, quien, en su primera edición, expresó incluso la creencia, un tanto nostálgica, de que sería imposible recuperar el texto perdido ${ }^{8}$. El editor y traductor de los Cynegetica al francés J. N. Belin de Ballu manifestó la misma opinión 9 .

En el breve volumen que consagra a la biografía y la producción literaria de Opiano, Th.H. Martin recoge los argumentos anteriores ${ }^{10}$ (final abrupto en IV 453, brevedad del libro IV, la Vita aludida) para postular la pérdida de un centenar de versos del libro IV y de otro completo, si es que llegó a ser escrito. Su aportación principal consiste en haberse percatado de que el libro IV relata la caza de la mayoría de los animales del libro III, pero solo de uno del II ${ }^{11}$; del resto se hubiera ocupado un libro V. Más adelante, profundizaré en esta tesis. En una línea semejante, la traducción de A. M. Salvini era precedida por unas "Notizie intorno ad Oppiano", escritas por W. A. Greenhill, quien subrayó la imperfección del libro IV y la hipotética pérdida del V12.

${ }^{4}$ J. Brodaeus, 1552, p. 118.

5 J. Bodinus, 1555, f. 42 v.

${ }^{6}$ J. Bodinus, 1555, f. $98 \mathrm{v}$.

7 C. Rittershusius, 1597, p. 118 (de los Comentarii); además, cf. p. 339 (comentario correspondiente a V 675 de los Halieutica).

${ }^{8}$ J. G. Schneider, 1776, p. 379: "Mutilum esse poema hoc cuiuis apparet; nec eius redintegrandi ulla spes est". Schneider acaba el texto editado con la frase $\Lambda \varepsilon^{\prime} i \tau \varepsilon \iota \tau \dot{\alpha} \varepsilon^{\xi} \xi \tilde{\eta} s$ (p. 65) y escribe con relación a III 406 (p. 371): "Hic vero locus arguit mancum Oppiani de venatione poema ad nos pervenisse; nullibi enim apparet hystricum venatio".

9 J. N. Belin de Ballu, 1786, p. 343: "In quinto fortasse libro dixerat nunc deperdito", dice a propósito de III 406; y acaba el texto editado con la misma frase que Schneider (p. 186). También en su traducción del poema al francés (1787, p. viii): "Encore le quatrième chant de ce dernier est-il incomplet et le cinquième totalement perdu; car ce poëme étoit, comme celui de la Pêche, divisé en cinc chants". En la p. 106: "Le reste est perdu". Y en la p. 197 escribe a propósito de III 406: "Lig. 14. Je parlerai. Sans doute il en avoit parlé dans le cinquieme chant de ce poëme; mais ce chant est perdu depuis long-temps".

${ }^{10}$ Curiosamente, su argumentación omite la promesa de III 404-6.

11 Th.-H. Martin, 1863, pp. 58-9: “car les 453 vers du quatrième chant enseignent à chasser la plupart des animaux décrits dans le troisième chant, mais il n'y est question que d'un seul des animaux décrits dans le second".

12 A. M. Salvini, 1864, p. xviii: "La Cinegetica consta di circa de 2100 esametri divisi in quattro libri, l'ultimo de' quali è imperfetto, ed eravi per avventura un quinto libro che andò perduto". 
Sebastián Martínez García

Los Cynegetica de pseudo-Opiano, ¿un poema incompleto?

En cambio, la crítica del siglo XX ha preferido creer que, al margen del epílogo, los Cynegetica no estaban incompletos. R. Keydell se percató de la mutilación final del poema, aunque no creía que tuviera un libro más, sino que otorgaba mayor credibilidad al léxico Suda que a las Vitae Oppiani ${ }^{13}$. Por su parte, E. Pöhlmann observó la ausencia de un epílogo, pero consideró que Opiano de Apamea había agotado la materia y, siguiendo el criterio de Keydell, prefirió el testimonio del Suda en lo que se refiere al número de libros del poema ${ }^{14}$. A su vez, G. Massimilla constata que el poema se interrumpe in medias res y que le falta el epílogo ${ }^{15}$. A. N. Bartley cree que el libro IV es el último, dado que la larga digresión sobre Dioniso y los leopardos que contiene ocuparía la misma posición que el excurso sobre el muchacho y el delfín del libro V de los Halieutica, poema que es imitado en los Cynegetica $^{16}$. Por su parte, G. Agosta considera que, en sustancia, el poema está completo y que no habría que pensar en un libro $\mathrm{V}$, dado que, en su opinión, el autor había agotado el tema ${ }^{17}$.

\section{Los argumentos tradicionales}

Tradicionalmente, quienes postulan que el poema está inacabado o incompleto se basan en la promesa incumplida de III 404-6, en la falta de epílogo después del verso IV 453 y, no tan a menudo, en el testimonio de una biografía bizantina sobre Opiano.

Veamos, de manera concisa, el primer argumento. Entre los depredadores del libro III Opiano sitúa algunos animales como el puercoespín, aunque, hoy en día, no lo clasificaríamos en esta categoría. Este gran roedor usa sus púas como armas defensivas, pero, según el poeta, las dispara poniendo en peligro a los perros de caza; por eso, los cazadores evitan emplear perros para capturarlo y se inclinan por otros recursos que el poeta promete explicar más adelante ${ }^{18}$. Pero en los 453 versos del libro IV, dedicados a la práctica de la caza, omite hablar del

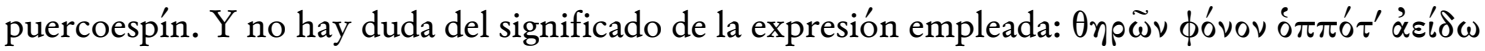
remite, sin posibilidad de error, a la descripción de las capturas. Sin embargo, sí que cumple otra promesa, la que había hecho en III 78-83, donde había anunciado que cantaría la metamorfosis de los leopardos ${ }^{19}$. Sus palabras se harán realidad en el largo excurso de IV 230-319.

Otro detalle que llamó la atención de los estudiosos sobre la naturaleza inacabada de los Cynegetica era, como ya hemos mencionado, la falta de epílogo ${ }^{20}$. Si observamos las obras de los autores de poesía didáctica que se pueden considerar cercanos al autor de Apamea, nos damos cuenta de que conceden gran importancia a los proemios y epílogos. Repasemos algunos de ellos.

El poeta helenístico Nicandro acaba sus poemas con su sphragís ${ }^{21}$, su sello, identificándose por su nombre y ocupación, según se puede leer en los Theriaca, añadiendo el nombre de su

13 R. Keydell, 1939, c. 705.

${ }^{14}$ E. Pöhlmann, 1973, pp. 872-3 y n. 369. Véase también B. Effe, 1977, p. 182, n. 19.

15 G. Massimilla, 1999, p. 195.

${ }^{16}$ A. N. Bartley, 2003, p. 20, n. 56.

17 G. Agosta, 2009, p. 12.

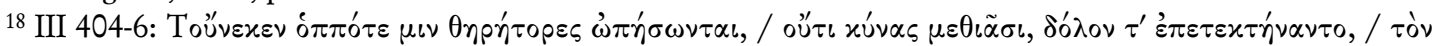

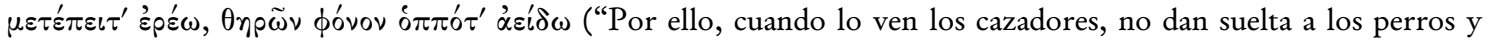
urden un engaño que luego contaré, cuando cante la muerte de las fieras"). Para las flechas de los puercoespines, cf. Arist., HA 623 a 32; Plin., HN VIII 125; Ael., NA I 31; Claudian., De hystr. Para los Cynegetica seguimos el texto de la edición de M. Papathomopoulos (2003); las traducciones son obra del autor.

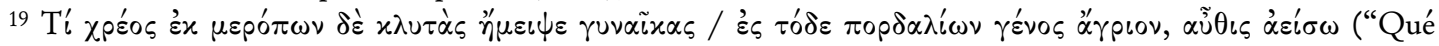
necesidad cambió de mortales a aquellas ilustres mujeres en este fiero linaje de panteras, más adelante cantaré”).

20 Sobre los epílogos de los poetas latinos, cf. K. Volk, 2002, p. 83 y n. 42. También interesa, aunque de manera tangencial, el artículo de W. Dominik, 2003, pp. 91-109. Además, para los proemios de los poetas griegos en tiempos del imperio romano, cf. M. Brioso Sánchez, 1996, pp. 55-133.

${ }^{21}$ Para los epílogos de Nicandro, cf. J.-M. Jacques, 2002, pp. LXX-LXXI; M. Brioso Sánchez, 1996, pp. 82-3; para la falta de epílogo en el poema de Arato, cf. M. Brioso Sánchez, 1996, p. 78. En general, sobre la sphragís, cf. W. Kranz, 1961, pp. 3-46 y 97-124. 
patria, y en los Alexipharmaca, donde llama a venerar a Zeus Xenios. De una manera parecida, Virgilio pone fin a las Georgicae (IV 559-66), marcando el poema con el sello de su nombre, además de hacer alusión a sus Eclogae ${ }^{22}$. Ovidio, en el epílogo de las Metamorfosis (XV 871-8), reclama la inmortalidad para su obra, después de haber anunciado el final de su poema; en el Ars amatoria (III 809-12), en cambio, señala el final de su viaje poético, pero sella el poema con su nombre; en los Remedia amoris (811-4) acaba con la metáfora de la navegación, donde la nave que llega a puerto es la metáfora del poema acabado, y reclama además el agradecimiento de las generaciones venideras ${ }^{23}$. Por su parte, Dionisio Periegeta culmina la Descripción de la tierra con unos cuantos hexámetros (1181-6), en que, despidiéndose de los accidentes geográficos, da por acabado su recorrido y pide a los dioses una recompensa por su obra ${ }^{24}$.

Los Halieutica de Opiano de Cilicia, que, como es sabido, son el modelo principal del poeta de Apamea, acaban con una interpelación al emperador, cuyos versos (V 675-80) ponen

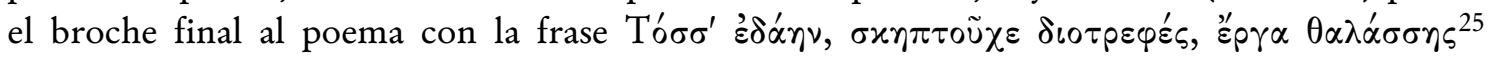
(“Tanto aprendí, señor del cetro, vástago de Zeus, de las obras del mar”) y, acto seguido, invocan el favor de los vientos, del mar y del propio Posidón para con el emperador. A su vez, cierto individuo de nombre Dionisio compuso un poema sobre la captura de las aves o Ixeutica, un escrito de estilo cercano a los Halieutica y a los Cynegetica, del cual solo se conserva una paráfrasis en prosa (editada a menudo con el título De aucupio). Probablemente el poeta escribió un final semejante al epílogo de Opiano de Cilicia, ya que en III 25 hallamos también una frase conclusiva ${ }^{26}$ y una significativa alusión a Apolo como fuente de los conocimientos del poeta ${ }^{27}$.

Pero no se encuentra nada de todo eso en los versos finales de los Cynegetica, nada indica que el verso IV 453 y los anteriores, dedicados a la caza del zorro, sean el final del poema. Y, sin embargo, parece que tendría que ser de otra manera: argumentos semejantes a los que hemos visto en otras obras didácticas (la imagen ovidiana del carro o de la nave de la poesía, la dedicatoria al emperador, el sello haciendo alusión a la patria o al nombre del autor, una referencia a la divinidad inspiradora del poema...), especialmente en los Halieutica y en el De aucupio, le habrían sido útiles para poner colofón a su trabajo.

En tercer lugar, queda por tratar el hecho de que la Vita $\beta$, ya invocada por C. Rittershusius, testimonia que los Cynegetica (como también los Ixeutica que esta Vita atribuye a Opiano) tenían cinco libros ${ }^{28}$. En cambio, el léxico $S u d a$, el primero que atribuye a Opiano los Halieutica, los Cynegetica y los Ixeutica, asigna al poema de la caza el número de libros que tiene actualmente ${ }^{29}$. P. Hamblenne explicó estos números por la pretensión de los biógrafos de encajar el número de versos con la recompensa en monedas de oro que, según la tradición iniciada

22 Cf. R. A. B. Mynors, 1990, pp. 323-4.

23 Para los epílogos del Ars y de los Remedia, cf. R. K. Gibson, 2003, pp. 403-4.

${ }_{24}$ Para el doble epílogo de Dionisio y sus antecedentes, cf. M. Brioso Sánchez, 1996, p. 102; E. Magnelli, 2005, pp. 105-8.

${ }^{25}$ En palabras de E. Kneebone (2008, p. 32): "signals the end... and encapsulates the poetical project of the Halieutica”. Sobre este epílogo, cf. J. C. Iglesias Zoido, 2002, p. 291. Sobre la estructura del poema en general, cf. E. Rebuffat, 2001, pp. 39-63.

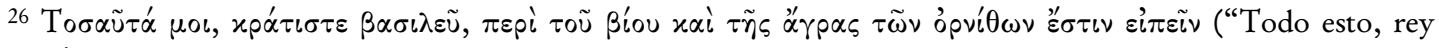
poderosísimo, me es posible decir acerca de la vida y captura de las aves”).

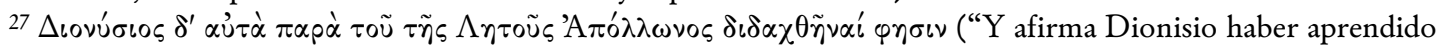
esto de Apolo, el hijo de Leto").

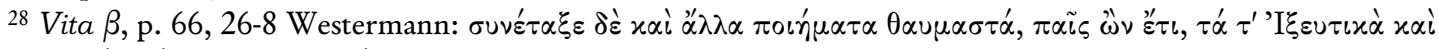

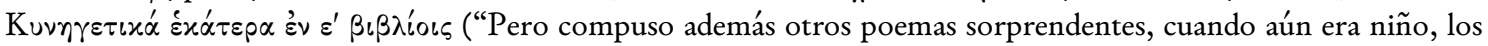
Ixeutica y los Cynegetica, cada uno en cinco libros").

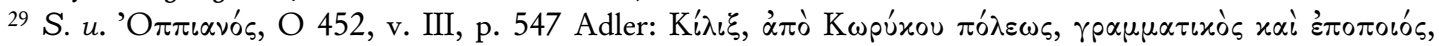

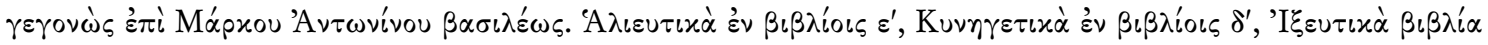
$\beta^{\prime}$ ("Opiano, cilicio de la ciudad de Córico, gramático y épico, que vivió bajo el emperador Marco Antonino, Halieutica en cinco libros, Cynegetica en cuatro libros, Ixeutica dos libros”). 
Sebastián Martínez García

Los Cynegetica de pseudo-Opiano, ¿un poema incompleto?

por Sozómeno, percibió el poeta de manos del emperador ${ }^{30}$. En todo caso, parece que, al menos en este punto, la Vita $\beta$ puede no ser fiable, dado que ni siquiera se encuentra en manuscritos que contienen los Cynegetica ${ }^{31}$.

\section{La caza en el libro II}

Como hemos visto anteriormente, los partidarios de considerar que el poema está completo reiteran que Opiano había agotado su materia y que ya no le quedaba nada más que aportar; no obstante, en los libros II y III es posible encontrar alusiones a la captura que constituyen un motivo suficiente para pensar de otra manera. Opiano sabía mucho más al respecto, como veremos a continuación.

Entre otros animales, en el libro II el autor describe los ciervos y toma nota de sus cuernos romos, inservibles para la lucha; concretamente en II 184-6 dice que ni los usan contra las fieras, ni contra los perros, ni siquiera contra las liebres ${ }^{32}$. La mención de los perros nos introduce en un contexto cinegético: la caza del ciervo. En el poema ya se había hecho referencia al uso de caballos (I 307) para cazarlos, además de la práctica de esta modalidad por parte del mitológico Perseo (II 13). Su captura, no obstante, no es relatada en los Cynegetica.

Un poco más adelante, en II 308-10, el poeta sirio habla de los antílopes. Estos herbívoros echan de menos los lugares a los que están acostumbrados, de manera que no tardan en volver a ellos, una vez liberados por los cazadores, que los han capturado mediante lazos y se los han llevado lejos ${ }^{33}$. Sin embargo, después de este comentario, ya no se vuelve a tocar el tema de la caza del animal.

El libro II pasa a describir las gacelas: manifiestan un extraño comportamiento que las lleva a buscar la compañía de las perdices y viceversa, pero este afecto las pone en peligro, ya que los cazadores emplean perdices para atraer a las gacelas ${ }^{34}$. Se trata, en efecto, de una demostración de astucia, de metis, por parte de los hombres, que se aprovechan de los extraños afectos de determinados animales. Tenemos, de nuevo, una referencia a la captura, que no se recoge en el libro IV, aunque allí, en 439-47, se habla de la caza de las gacelas (ignoramos si a pie o a caballo; de la primera manera las capturaba en el mito Perseo, según relata el propio Opiano en II 12), pero sin recurrir a las perdices.

En II 343-76 se desarrolla una detallada descripción del amor materno-filial de las cabras. Este sentimiento permite capturar a los cabritillos a aquel cazador que se haya apoderado de la

30 Según lo explicó P. Hamblenne (1968, pp. 611-2 y 615), las veinte mil monedas de oro que, de acuerdo con el Suda, recibió Opiano, equivaldrían a cinco mil estateras antiguas, la suma aproximada de los versos de los Halieutica y de los Cynegetica (es decir que los dos libros de los Ixeutica que el Suda atribuye también a Opiano no valían nada). En cambio, siempre según Hamblenne, la Vita atribuye cinco libros a cada obra para justificar el total de veinte mil monedas de oro; su cálculo sería que Opiano había escrito tres poemas de extensión semejante a los Halieutica, que, en números redondos, serían algo más de diez mil versos, porque había recibido diez mil estateras que, en peso, equivalían a veinte mil monedas del siglo XI.

${ }^{31}$ Esta Vita fue publicada por A. Westermann (1845, pp. 65-6), probablemente (cf. T. Silva Sánchez, 19941995, p. 108, n. 5) a partir de los códices Vaticano-Palatinus gr. 96 (siglo XVI; designado con la sigla $\mathrm{P}_{2}^{2}$ por Fajen, 1969) y Heidelbergensis Palatinus gr. 40 (siglo XIV; con sigla $P_{1}$ en Fajen).

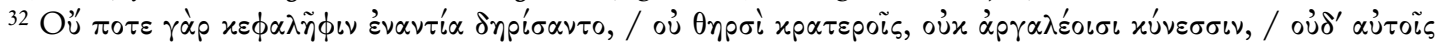

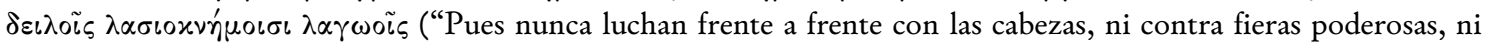
contra dañosos perros, ni siquiera contra las cobardes liebres de peludas patas").

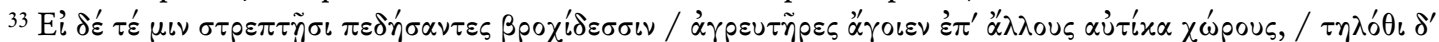

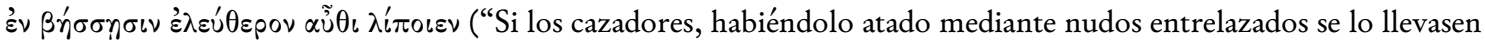
al punto a otras tierras y libre lo dejasen otra vez lejos, en unos valles”).

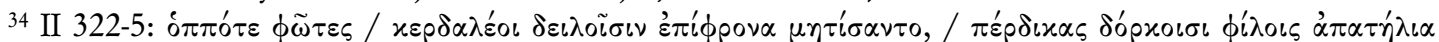

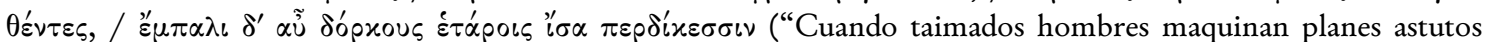
contra estos desdichados, ya que para las amistosas gacelas emplean perdices como reclamo y, a su vez, emplean con el mismo fin gacelas contra las perdices”). Para esta amistad, cf. Opp., C. II 405-6 y 428-30; Tim. Gaz., p. 9,2 Haupt. Véase también S. Martínez, 1995, pp. 86-7. 
madre, dado que los hijos se le entregan voluntariamente ${ }^{35}$. Como en los casos anteriores, no se vuelve sobre este tema en el libro IV (aunque las cabras salvajes son presas habituales, como leemos en I 71, y su captura se remonta también a Perseo, como se lee en II 11), pero, en esta ocasión, se puede creer que el argumento estaba agotado.

Después de haber escrito sobre cérvidos y cabras, el poeta de Apamea pasa a caracterizar un herbívoro cornúpeta desconocido para nosotros ${ }^{36}$, el subo (II 382-444). Este animal le sirve para introducir un excurso sobre el poder de Eros, puesto que, cuando atraviesa el mar, despierta una fascinación portentosa en los peces, pero su naturaleza malvada lo hace devorar a sus admiradores. Este comportamiento es aprovechado por el autor para imprecar la muerte del animal a manos de los cazadores, que usarán algún tipo de trampa marina ${ }^{37}$. Otra vez nos hallamos ante una forma de captura de la cual no se hace eco el libro IV.

Acto seguido, el poeta se ocupa del órix (II 445-88), que destaca por su carácter colérico y por la extrema peligrosidad de sus cuernos; de este modo, no teme los perros de caza (II 456):

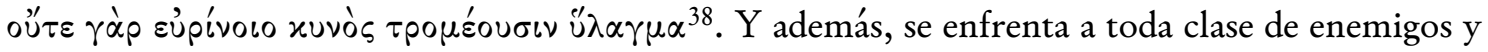
a menudo provoca incluso la muerte de los cazadores ${ }^{39}$. Por otra parte, el órix fue una presa más de Perseo (II 12). A pesar de estas alusiones cinegéticas, la captura de este animal también es omitida en el libro IV.

No abandonamos todavía nuestro protagonista animal, ya que el órix, que adelanta los cuernos y espera al depredador que se le echa encima, es comparado con el cazador que espera a pie firme la acometida de un león ${ }^{40}$. La caza de ese felino, en tres modalidades distintas, inicia las descripciones de caza del libro IV y ocupa aproximadamente su cuarta parte: Opiano describe la captura en fosos practicada en Libia, las cacerías en tierras del Éufrates con antorchas y caballos que conducen a los leones dentro de las redes ${ }^{41}$, y finalmente la lucha hasta la extenuación de la fiera y su derrota en Etiopía. El argumento del símil, por tanto, no se cuenta entre las capturas descritas en el libro IV, donde tampoco aparece el empleo de perros mencionado en I 417. Da la impresión de que el poeta se conforma con lo ya escrito y considera suficientes sus tres relatos de IV 77-211.

\section{La caza en el libro III}

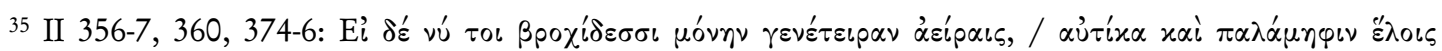

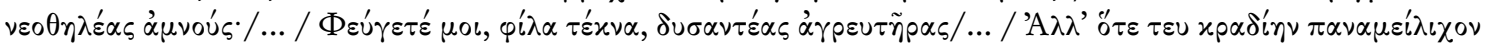

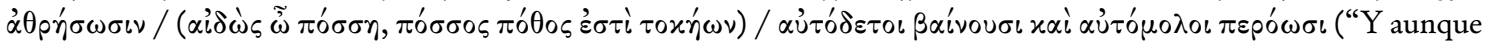
con lazos solo capturases a la progenitora, al punto también cogerás con las manos los cabritillos recién nacidos... Huid, os suplico, amados hijos, de los cazadores de funesto encuentro... Mas cuando contemplan tu corazón insensible -su veneración, ¡qué grande es!, ¡qué grande el amor a los padres!-, por propia voluntad vienen atados y por su propio paso se acercan."). Sobre el tema del amor y el cuidado que tienen los animales para con sus hijos y recíprocamente los hijos para con sus progenitores, cf. S. Martínez, 1996, pp. 93-102.

${ }^{36}$ Resume las hipótesis acerca de la identidad del animal P. Cipolla (2006, pp. 518-9).

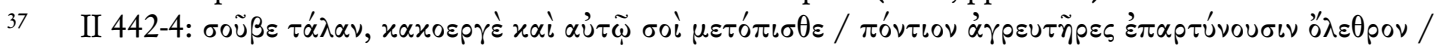

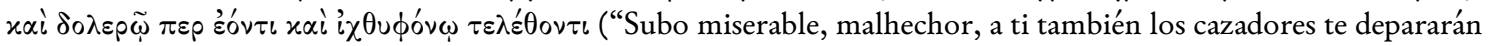
la perdición en el mar, aunque seas falaz y te muestres como asesino de peces”).

38 "Pues ni siquiera tiemblan ante el ladrido del perro, buen olfateador".

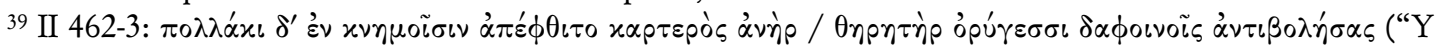
muchas veces en las cumbres ha muerto un hombre robusto, un cazador, en un encuentro con los sanguinarios órices").

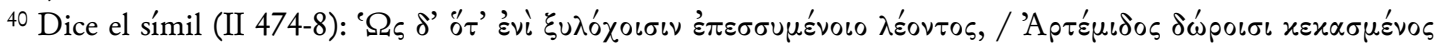

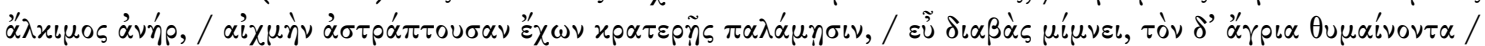

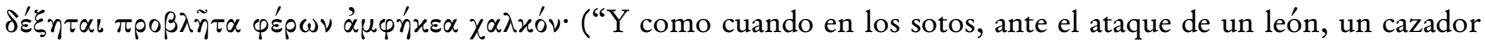
robusto, avezado en los dones de Ártemis, sosteniendo bruñida lanza en las fuertes manos, espera, firme sobre sus piernas abiertas, a la bestia y la recibe, ferozmente encolerizada, poniendo en vanguardia el bronce de doble filo”.

${ }^{41}$ El uso de caballos ya había sido anticipado en I 310. 
Sebastián Martínez García

Los Cynegetica de pseudo-Opiano, ¿un poema incompleto?

El poeta comienza, tras un conciso proemio, el libro III con la descripción de leones, leopardos y linces, y pasa a narrar el extraordinario afecto que profesan estas fieras, así como los tigres, a su prole (96-138). En el pasaje se alude a un tipo de captura en que los cazadores aprovechan la ausencia de las madres para apoderarse de los cachorros ${ }^{42}$, circunstancia que no es recogida en el libro IV, quizá porque no fuera digna de las cacerías reales. El amor de las hembras por la prole es todavía objeto de unas líneas en este libro $\mathrm{III}^{43}$, donde también se loa el amor materno, pero el planteamiento cambia manifiestamente, ya que ahora no se trata de cazadores que se apoderan de los cachorros sacándolos de las madrigueras, sino de un verdadero ejército, que, usando armas de todo tipo, avanza frente a ellas.

A continuación, el poeta presta atención a dos animales (oso y onagro), cuya actitud contrasta fuertemente con los anteriores. Acto seguido, se ocupa de diversas bestias, hasta que llega el turno del tigre. De nuevo, encontramos un tipo de captura diferente: se emplean redes donde quedan retenidas las tigresas, que buscan a los cachorros ${ }^{44}$. Así pues, en el libro III se hace referencia a tres tipos de caza (robo en la madriguera, ataque en tropel y uso de redes) para los felinos mayores, ninguno de los cuales aparece en el libro IV y tampoco se menciona en él que los jinetes ataquen tigres (I 75) y leopardos (I 308).

Como hemos dicho anteriormente, Opiano de Apamea describe, antes de los tigres, otros animales, entre ellos los caballos salvajes, que, como los antílopes mencionados anteriormente, son capturados con lazos y aceptan con desagrado su nueva vida ${ }^{45}$. Esta manera de hacerse con los caballos salvajes, así como los antílopes, falta también en el libro IV.

Inmediatamente después del tigre, Opiano describe el jabalí y, entre sus características, menciona el poder de los colmillos, que pueden abrasar una cerda o quemar la piel de los perros, como pueden comprobar los cazadores después de matar uno ${ }^{46}$. La caza del jabalí, que lleva a cabo una multitud de hombres armados con lanzas y acompañados de perros (cf. también I 416),

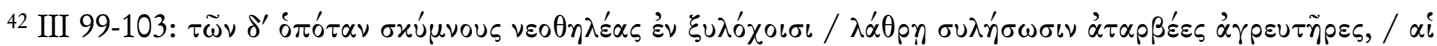

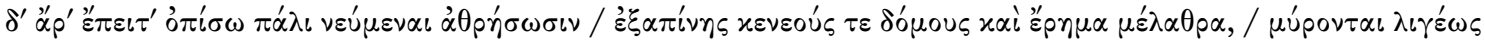
ádıvòv yóov ("Y cuando en los sotos los imperturbables cazadores se apoderan a escondidas de sus jóvenes cachorros, las hembras, tan pronto como vuelven al cubil y contemplan la casa inesperadamente vacía y la residencia solitaria, se lamentan melodiosamente con llanto inacabable"). Sobre el tema del amor parental de los animales, cf. S. Martínez, 1996, p. 93-102. Para diferentes versiones de estos comportamientos, cf. Plu., Mor. 493-7 es decir, todo el tratado De amore prolis); 966 b; Opp., H. I 702-8 (pasaje que inspira este texto del poeta de Apamea); Ael., NA VI 61; IX 1.

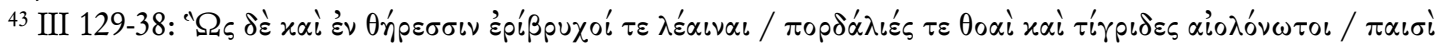

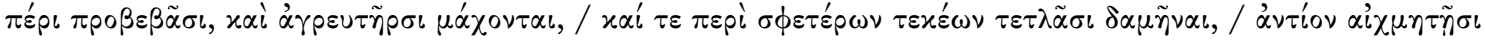

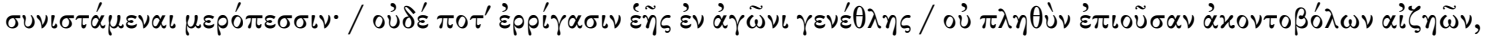

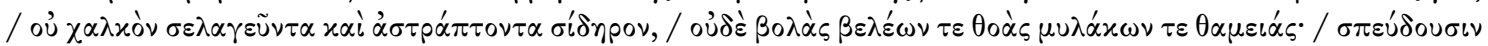

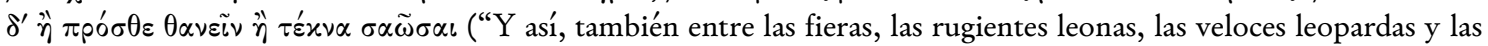
tigresas de veteado lomo se adelantan en defensa de los cachorros y luchan contra los cazadores y, por amor a los hijos, aceptan someterse, entablando combate con los lanceros; en la lucha por su descendencia, nunca temen al tropel de hombres armados que avanza, ni el bronce resplandeciente ni el brillante hierro ni los raudos dardos de las flechas ni de las abundantes pedradas: se afanan por morir en combate o salvar a los cachorros").

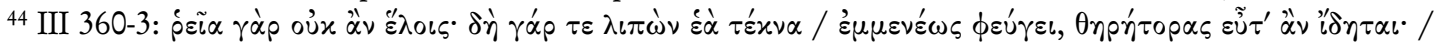

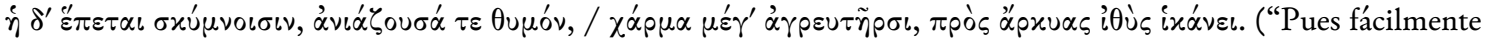
no lo capturarías; pues, tras haber abandonado sus cachorros, huye a toda prisa, tan pronto como divisa a los cazadores. Ella, en cambio, acompaña los cachorros y, con el corazón atormentado, jinmenso gozo de los cazadores!, va derecha a las redes"). Para su comportamiento con los cachorros, cf. Plin., HN VIII 66; Claudian., In Ruf. I 90.

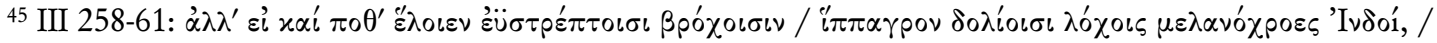

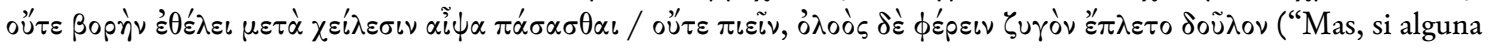
vez los indios de negra piel capturan un caballo salvaje con flexibles lazos en dolosa emboscada, el animal no acepta en seguida tomar en su boca alimento ni beber y resulta fatal para soportar el yugo de la esclavitud").

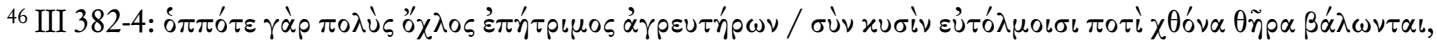

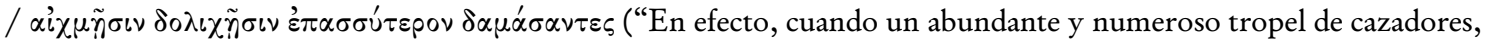
con valientes perros abate a tierra esta fiera, después de haberla sometido con repetidos disparos de largas lanzas”). 
no vuelve a reclamar la atención del poeta, aunque anteriormente había hecho referencia al uso de caballos para su captura (I 309) y había evocado a la mítica Atalanta, cazadora del jabalí de Calidón (II 27).

Un poco más adelante, el poeta describe las madrigueras de los zorros, muy adecuadas para escapar, y hace referencia a dos maneras de capturarlos ${ }^{47}$. El uso de lazos de nudo corredizo ( $\beta \rho \circ \chi\left(\delta \varepsilon \sigma \sigma \sigma \nu \alpha^{\prime} \gamma \omega \nu \tau \alpha \iota\right)$ suele fracasar, dado que el zorro huye de su refugio por otra salida. En

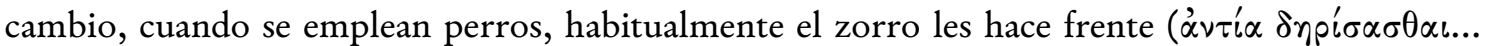

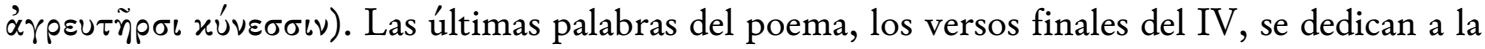
caza del zorro ${ }^{48}$ : en ellos se vuelve sobre dos procedimientos aludidos en el libro III, las trampas con lazo y la caza con perros, y se insiste en la facilidad del animal para zafarse de aquellas (oü $\tau \varepsilon$

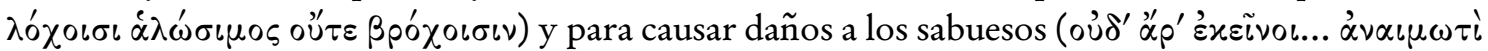
$\delta \alpha \mu \alpha \dot{\alpha} \sigma \alpha \nu \tau)$.

A punto de acabar el libro III, Opiano consagra unos versos a dos animales, que, según dice, son de naturaleza híbrida: la jirafa y el avestruz. Incluye entre las piezas de caza este último animal, aun siendo un ave, por el hecho de que para su captura se emplean recursos propios de la caza (caballos y lazos) y no de la captura de pájaros:

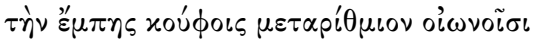

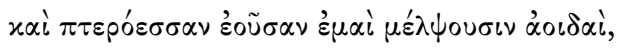

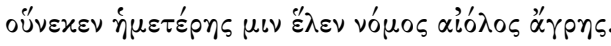

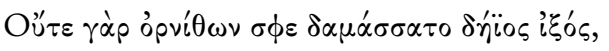

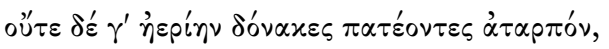

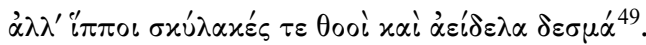

Nos volvemos a encontrar ante otra presa, el avestruz, de la que no se habla en el libro IV, como ocurre en bastantes ocasiones, según ya hemos visto en estas páginas, pero además en

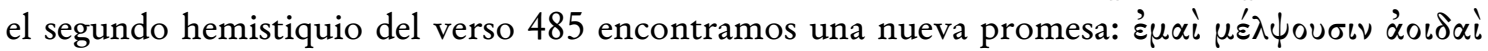

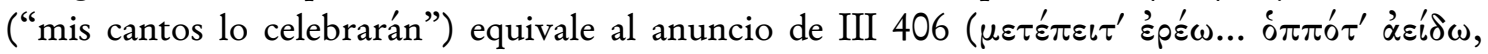
“...luego contaré, cuando cante...”).

Las últimas líneas del libro III (504-25) versan sobre las liebres, que el autor saluda así:

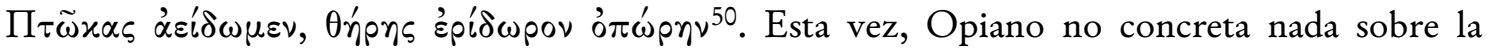

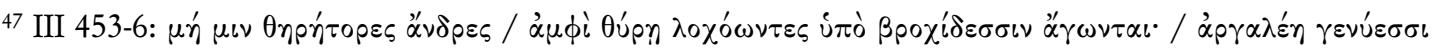

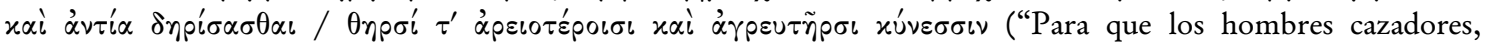
emboscados en la puerta, no se lo lleven con lazos. Es temible incluso cuando lucha a dentelladas contra fieras más belicosas y contra perros de caza"). Para la astucia y la fama de este animal, cf. O. Keller, 1909, pp. 88 s.; M. Wellmann, 1933, c. 189-92; M. Detienne - J. P. Vernant, 1969, pp. 291-317; C. García Gual, 1971, pp. 417-31; J. M. C. Toynbee, 1973, p. 102.

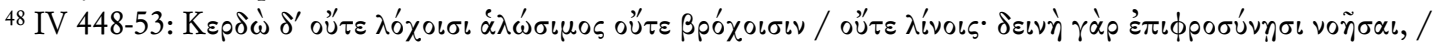

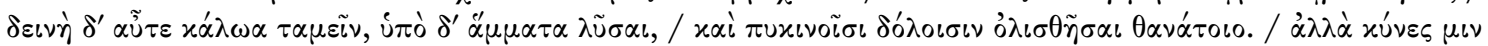

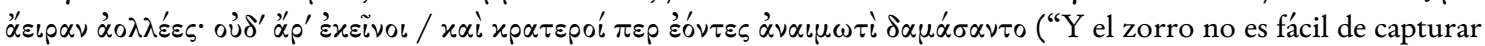
con emboscadas ni con lazos ni con linos. Pues por su sensatez es hábil para darse cuenta de ellos y hábil para cortar hilos, librarse de ataduras y, con sagaces tretas, escurrirse de la muerte. Con todo, los perros lo capturan todos a una: pero ni ellos, aunque son vigorosos, sin derramamiento de sangre lo someten"). Para diferentes maneras de cazar el zorro, cf. Mart. X 37, 13-14; Nemes., Cyn. 307; véase F. Orth, 1914, c. 601; M. Wellmann, 1933, c. 18992.

49 III 484-9: “Aunque se cuenta entre las ligeras aves y es plumífero, mis cantos lo celebrarán, ya que lo captura el variado menester de nuestra caza. Y es que ni la liga, enemigo de las aves, lo somete, ni los juncos que recorren los senderos del cielo, sino caballos, veloces perros y ataduras invisibles". Para la definición de la naturaleza del avestruz, cf. Arist., PA 697 b 14; Plin., HNX 1; Paus. IX 31, 1. Para la caza del avestruz, cf. D. S. II 50; Ael., NA XIV 7; Str. XVI 4, 11; X., An. I 5, 2.

50 III 504: "Las liebres cantemos, de la caza generosa cosecha”. Para las liebres en general, cf. H. Gossen, 1912, c. 2477-86; O. Keller, 1909, pp. 210 s.; J. M. C. Toynbee, 1973, pp. 200-2. 
Sebastián Martínez García

Los Cynegetica de pseudo-Opiano, ¿un poema incompleto?

captura, pero hace alusión a su condición de presas importantes y, por eso, protagonizarán unos versos en el libro IV (425-38). Además, el adiestramiento de los perros para cazarlas había ocupado un largo pasaje del libro I (481-538); y, por otra parte, eran una de las piezas que cobraba Perseo (II 11).

\section{El trasfondo del libro IV}

En los apartados anteriores hemos visto que los libros II y III presentan, de manera muy diseminada, muchos pormenores sobre la captura de los animales y que, sin embargo, muy pocos están recogidos en el libro IV. Ahora sería conveniente estudiar el contenido del mismo. Si elaboramos una lista de los animales, cuya caza es relatada, con mayor o menor detalle, nos percataremos de que el libro IV sigue, a grandes rasgos, el esquema del III: león (77-210), chacal y leopardo (211-29), leopardo (230-353), oso (354-424), liebre (425-38), gacela (439-47) y zorro (448-53). En efecto, el libro III contiene el esquema del IV, pero aporta información sobre muchos otros animales ${ }^{51}$ : león (7-62), leopardo (63-83), lince (84-95), oso (139-82), onagro (183-251), caballo salvaje (252-61), lobo y hiena (262-335), chacal (336-9), tigre (340-63), jabalí (364-90), puercoespín (391-406), icneumón (407-48), zorro (449-60), jirafa (461-81), avestruz (482-503) y liebre (504-25). Salvo la gacela, todos los animales del libro IV han sido tratados en el III, pero además el orden que se sigue es muy parecido: león-leopardo-oso-liebre y, con cambio de lugar, chacal y zorro.

En cambio, las diferencias son abismales en comparación con el libro II, que trata de estos animales $^{52}$ : toro (83-158), bisonte (159-75), ciervo (176-299), antílope (300-14), gacela (31525), cabras y carneros (326-81), subo (382-444), órix (445-88), elefante (489-550), rinoceronte (551-69), guepardo, gato y lirón (570-85), ardilla (586-97), erizo (598-605), simios (606-11) y topo (612-28). Como ya apuntó Th.-H. Martin ${ }^{53}$, tan solo la captura de un animal del libro II, la gacela, es descrita en el IV. Resulta, por tanto, extraño que en el libro IV Opiano omita tantos animales, aunque los dos libros anteriores demuestran la extensión no solo de sus conocimientos zoológicos, sino también - y es lo natural, en una obra sobre la caza- cinegéticos.

Por otra parte, la ordenación del contenido de los libros II y III es bastante clara: después de los respectivos proemios, se inician con sendas partes principales (II 83-569 animales cornúpetas; III 7-460 animales depredadores), como explicita el propio autor en III 1-6 ${ }^{54}$. Después, en cada libro sigue un apéndice, una parte marginal, donde se añaden unos animales extraños a la materia que se desarrollaba hasta el momento. En el libro II estos animales inesperados son introducidos mediante el recurso de la praeteritio (II 570-71, 586, 598, 605, 612-3), mientras que en el libro III el autor se vale de una invocación a la Musa (III 461) ${ }^{55}$.

Quizá parezca excesiva la atención que hemos prestado a los libros II y III, pero no ha sido sin una finalidad. En contraste con la esmerada manera de presentar y estructurar esos contenidos, al examinar el libro IV, se observa un cambio difícil de explicar: después de un

51 Para el contenido del libro III, cf. G. Agosta, 2009, p. 93.

52 Sobre el contenido del II, cf. G. Agosta, 2009, pp. 92-3.

53 Th.-H. Martin, 1863, pp.58-9.

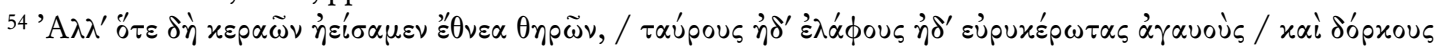

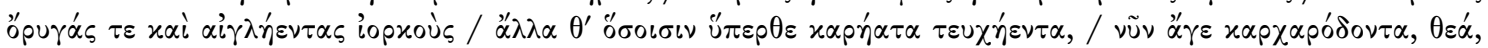

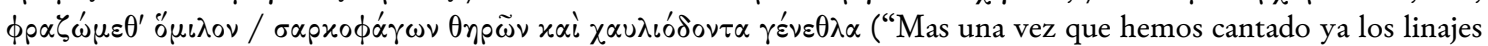
de los animales cornúpetas, toros, ciervos y magníficos corniabiertos, gacelas, órices y resplandecientes corzos, y cuantos poseen cabezas armadas por arriba, ahora ven, diosa, describamos la multitud de dientes afilados de fieras carnívoras y los linajes dotados de salientes colmillos"). Simplifico un tanto, dado que, de hecho, el poeta no habla en realidad de depredadores, sino que, como se ve en el texto, hace referencia a la dentición (los animales armados con dientes afilados o colmillos) y a la alimentación (carnívoros). Sobre esta división, cf. T. Silva Sánchez, 1994-95, p. 117, n. 70, y 2002, p. 160, n. 407; G. Agosta, 2009, pp. 89-90.

55 Mientras que los animales marginales del libro II parecen indignos de la caza, los del libro III resultan presas interesantes (quizá no las jirafas, que acaso sean introducidas por la relación que se les atribuye con los leopardos). 
proemio que, entre otros temas, enlaza este libro con los anteriores y anuncia su contenido ${ }^{56}$, se inicia la narración de diversas capturas, introduciendo primero la caza del león (IV 77-8), de una forma parecida a la empleada en II 43-4 para introducir la descripción de los toros y en III 7 para iniciar la descripción de los leones. Desde ese punto se desarrolla la parte principal del IV, que describe la captura de los depredadores (león, chacal, leopardo y oso). A continuación, encontramos una parte marginal (425-53), que contiene la caza de liebres, gacelas y zorros, pero que, al contrario que en los libros II y III, aparece yuxtapuesta, sin usar ningún elemento relacionante ${ }^{57}$.

Por tanto, llaman poderosamente la atención las acentuadas diferencias entre el comienzo del libro IV (con la recapitulación de los versos 1-3, la anticipación de los versos 4-7 y el incipit de 77-8) y su final (sin transición en el verso 425 ni epílogo); del mismo modo, también resultan llamativas las diferencias con los libros II y III; e igualmente resulta notable el bajo número de capturas narradas en el libro IV en comparación con el elevado número de especies animales tratadas en II y III, y las numerosas referencias a la captura en estos dos libros.

Pero volviendo sobre la escasez de capturas relatadas en el libro IV, todavía resulta más llamativa si se presta atención a unos versos del proemio:

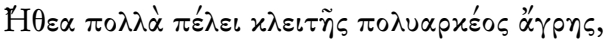

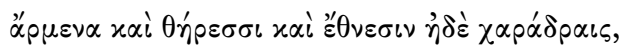

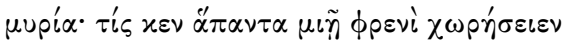

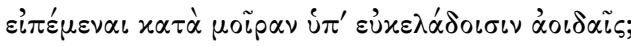

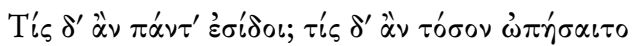

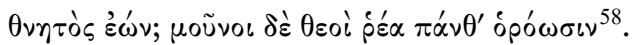

Se podría creer que Opiano emplea el tópico de las limitaciones humanas ${ }^{59}$ para abreviar su poema o para excusar datos que ignora, que le parecen inadecuados para un poema de esta naturaleza o de los que carece de informes fidedignos. Pero inmediatamente el poeta se dirige a Ártemis:

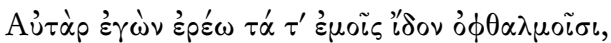

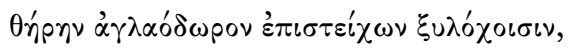

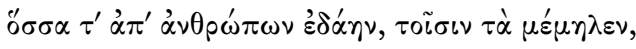

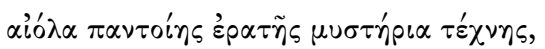

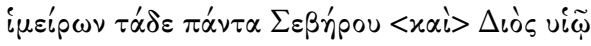

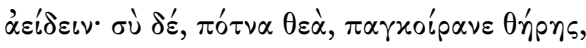

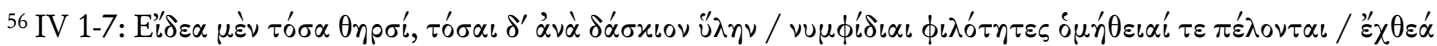

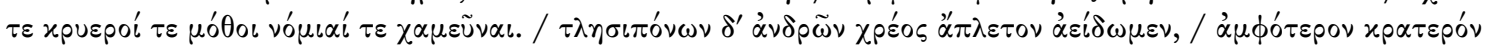

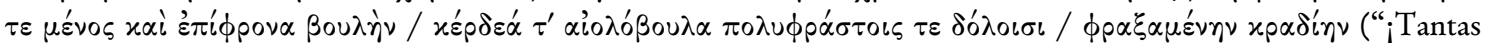
son las estampas de las fieras, en el umbroso bosque tantos los amores nupciales, las vecindades, los odios, los combates crueles y las campestres yacijas! Mas cantemos el inmenso provecho de hombres denodados, su fuerte vigor junto con su sensato consejo, sus astutos designios y su corazón henchido de diestros engaños").

57 Sobre estos términos que, como puntos nodales, estructuran el discurso del poema didáctico, cf. G. Agosta, 2009 , p. 28.

58 IV 10-5: "Numerosos son los usos de la ilustre captura generosa, apropiados para los animales, sus razas y los barrancos; mil son. Con un solo intelecto, ¿quién sería capaz de contarlos todos, como es debido, en melodiosos cantos? ¿Quién los observaría todos? ¿Quién los contemplaría, tantos como son, siendo mortal? Solo los dioses ven todo fácilmente".

${ }^{59}$ Para el lugar común de las limitaciones humanas y poéticas, cf. Od. IV 379; X 305-6; Verg., G. II 42; Opp., H. I 85-92; D. P. 1169.Véase también el completo y profundo trabajo de M. Cariou, 2016, pp. 50-1. 
Sebastián Martínez García

Los Cynegetica de pseudo-Opiano, ¿un poema incompleto?

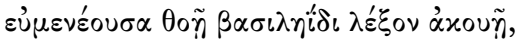

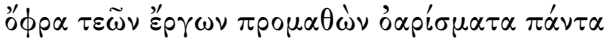

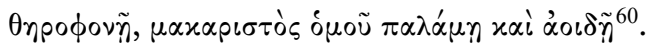

Así pues, el poeta concibe su canto como el resultado de su experiencia personal y de la práctica de los cazadores, pero es la propia diosa Ártemis quien culmina la formación cinegética del emperador ${ }^{61}$. Opiano se refugia, por así decir, en la diosa y le transfiere, en su nivel superior, el papel didascálico implícito en un Lehrgedicht. Pero en lo relativo al tema que nos ocupa, los versos son definitivos, dado que el autor pretende poner al alcance del emperador toda la ciencia cinegética (ó $\left.\alpha \rho^{\prime} \sigma \mu \alpha \tau \alpha \pi_{\alpha}^{\prime} \alpha_{\tau} \tau \alpha\right)^{62}$. En efecto, en estos versos hay una gradación desde la limitada experiencia de Opiano ${ }^{63}$, pasando por los amplios conocimientos de los cazadores ${ }^{64}$ sobre todo $^{2}$ aquello que solo sabe un iniciado ( $\mu \cup \tau \tau^{\prime} \rho\llcorner\alpha$, dice en griego), hasta la sabiduría de la divinidad. Por ello, resulta incoherente con estas palabras el hecho de que el poeta se conforme con las pocas narraciones de capturas relatadas en el libro IV.

Por último, otro aspecto llamativo es la omisión de determinadas capturas tradicionalmente tan relevantes como las del jabalí o el ciervo, y de otras tan interesantes por su exotismo como la del elefante ${ }^{65}$, ya que, como hemos visto, Opiano tenía ciertos conocimientos al respecto y además con estas narraciones podía despertar el interés del público y, en particular, del emperador. En este sentido, es sabido que el emperador Caracalla, a quien se dirige la obra, practicaba la caza de leones y jabalíes ${ }^{66}$; la primera está notablemente bien representada en el comienzo del libro IV, pero de la segunda no se dice ni una palabra. Por otra parte, resulta asimismo sorprendente el hecho de que el autor sirio haga solo unas mínimas alusiones a Aquiles (a su victoria sobre Memnón en II 154-5) y a Alejandro Magno (a Bucéfalo en I 229-30) ${ }^{67}$, aunque eran tan admirados por Caracalla, mientras que los otros dos personajes favoritos del emperador, Heracles y Dioniso, reciben un extenso tratamiento ${ }^{68}$.

60 IV 16-24: "Mas yo, por mi parte, describiré lo que vi con mis ojos, practicando la caza generosa en los sotos, cuanto aprendí de los hombres que se ocupan de ello acerca de los diversos misterios de una práctica deleitosa y variada, y quiero cantar todo ello en honor del hijo de Severo y de Zeus. Mas tú, diosa soberana, reina de la caza, seme propicia y díselo al atento oído real, para que, previamente instruido en todas las confidencias de tus labores, cace fieras, dichoso por su brazo y, a la vez, por mi poema".

${ }^{61}$ Para la figura de la diosa en los Cynegetica, cf. Z. Kádár, 1966, y A. Bartley, 2016.

62 Para el sentido y formación del neologismo óápı $\mu \alpha \alpha$, “conversación, confidencia”, cf. O. Rebmann, 1918, p. 114.

${ }^{63}$ Las experiencias que declara son haber visto en persona un león negro (III 46-7) y un avestruz (III 482-3), circunstancias que, en realidad, no son necesariamente cinegéticas. R. Keydell (1939, c. 706) deduce de II 32-3 y de IV 16-7 que el poeta practicó la caza.

64 Para los conocimientos que Opiano atribuye explícitamente a los cazadores, cf. I 399-400. Además, se hace eco de aportaciones de expertos en caballos (I 173-4) y cuidadores de leones (III 53).

65 Además de todas las mencionadas en las páginas anteriores, aún encontramos alusiones a la caza de otros animales como el chacal (I 70, II 11), el rinoceronte (I 70), el elefante (I 71), el lobo (I 72) y el toro (I 415). Pese a M. Błaśkiewicz (2014, pp. 33 y 37), Opiano no describe la caza del elefante.

${ }^{66}$ Cf. D. C. LXXVII 10, 1; Hist.Aug., Caracall. 5, 9 (Excepit apros frequenter, contra leonem etiam stetit, cf.

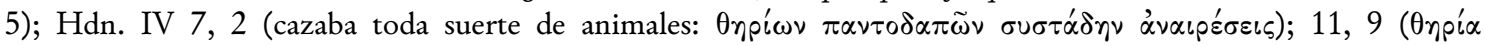
$\pi \alpha \nu \tau 0 \delta \alpha \pi \dot{\alpha} \alpha \dot{\alpha} \alpha \iota \rho \tilde{\omega} \nu)$. Para su representación en monedas y gemas, cf. O. Keller (1909), p. 43. Sobre Caracalla y la caza, cf. G. Agosta, 2009, p. 23; T. Silva Sánchez, 1994-1995, pp. 112-3; 2016, p. 256. Su afición queda reflejada incluso en la Vita $W$, aunque quizá su autor la dedujera del propio poema.

${ }^{67}$ Para la identificación de Caracalla con Alejandro Magno, cf. Hist.Aug., Caracall. 2, 1-2; Hdn. IV 8, 1-2; 9, 3-4; D. C. LXXIII 9, 1. Para su asimilación con Aquiles, cf. Hdn. IV 8, 4-5; 9, 3. En general, cf. J. Aymard, 1951, pp. 546-7; T. Silva Sánchez, 1994-1995, pp. 116-7; G. Agosta, 2009, pp. 12-3.

68 Y también en el plano mítico se echan de menos algunos relatos, por ejemplo, la caza del jabalí de Calidón (aludida de forma escueta en II 26-7) o las narraciones acerca de los cazadores fracasados (sobre el tema, cf. S. Martínez, 2000). 


\section{Conclusión}

Abundan los indicios que permiten sospechar que los Cynegetica están incompletos. En primer lugar, el hecho de que se incumpla la promesa de III 404-6, ya constatado por Brodaeus, cobra más relevancia si se tiene en cuenta que sí se lleva a término otro compromiso: el de cantar la metamorfosis de las bacantes (IV 230-319), como se había anunciado en III 78-83. Sin embargo, como hemos señalado, no se trata del único anuncio frustrado, dado que en III 484-6 sucede algo semejante con la caza del avestruz.

En segundo lugar, la falta de un epílogo del libro IV y del poema, señalada por Rittershusius, y la falta de transición hacia su parte marginal podrían ser insignificantes en sí mismas, pero esas carencias contrastan fuertemente con la cuidadosa ordenación y estructuración de los otros tres libros del poema ${ }^{69}$ y del mismo comienzo del libro IV.

Finalmente, la brevedad del libro IV en comparación con los otros tres, apuntada también por Rittershusius, no puede ser tomada per se como un argumento, pero la escasez de su contenido en contraste con todo lo que el autor expone previamente resulta, cuando menos, significativa: entre los libros II y III se describen, salvo error u omisión, 35 animales, mientras que en el IV solo se habla de la captura de siete. Asimismo, como hemos visto en nuestro repaso del contenido de los libros II y III, Opiano sabía sobre la caza mucho más de lo que dice en el libro IV; lo demuestran las numerosas referencias a la captura, que, de manera más o menos detallada, realiza y que se encuentran repartidas por los libros I, II y III. Solo una mínima parte de estos conocimientos queda recogida en el libro $\mathrm{IV}^{70}$. Es indudable que, aunque se puede alegar que algunos relatos no encajaban en la descripción de las capturas ${ }^{71}$, otros podrían haber sido incorporados a la parte final de la obra ${ }^{72}$. Todo ese saber cinegético podría haber sido recogido en un hipotético libro $\mathrm{V}$, donde quedarían reflejados el contenido y el esquema del libro II, del mismo modo que el libro IV recoge el esquema del III.

Y esa parquedad en cuanto al contenido extraña aún más, cuando en el proemio del libro IV hay una voluntad de compleción, que no se lleva a cabo en los versos conservados: IV 10-5

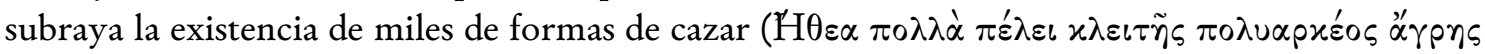
/ ... / $\mu$ upía) y junto con la propuesta de IV 24, la petición a la diosa para que instruya al emperador en todos sus conocimientos (’o $\left.\alpha \dot{\prime} \sigma \mu \alpha \tau \alpha \tau^{\prime} \alpha \nu \tau \alpha\right)$, mueven a pensar que el propósito de Opiano no era narrar solamente nueve procedimientos de caza ${ }^{73}$.

${ }^{69}$ El poeta muestra el mismo esmero en la construcción del libro I (aspecto al que aún no nos habíamos referido): en el v. 16 anuncia el propósito de cantar la caza; en los v. 35-40 concreta el argumento del poema a través del encargo que le hace la diosa Ártemis; en los v. 79-80 señala el final del proemio y en el v. 81 indica el comienzo del canto sobre la caza propiamente dicha; los v. 368-9 sirven como transición del pasaje sobre los caballos a los versos que dedica a los perros de caza. Al respecto, cf. T. Silva Sánchez, 1994-1995, pp. 113-7; M. Brioso Sánchez, 1996, pp. 104-5; G. Agosta, 2009, pp. 8-9.

70 De hecho, solo encontramos dos casos, procedentes del libro III (caza del zorro y de la liebre).

71 Del libro II, la captura de las cabras (como allí trata el tema detenidamente, habría evitado repetirse en el IV), de la gacela (de la cual trata otro aspecto en el IV) y del león (se ocupa de otras tres capturas en el libro IV). Del libro III, las referencias a la captura de las hembras de los felinos.

72 Del libro II, la caza del ciervo, del antílope, del subos y del órix; del libro III, la caza de los caballos salvajes, del jabalí y del avestruz, aparte de la caza del puerco espín, a la que hemos hecho tantas referencias.

73 Se describen tres procedimientos para el león (77-111, 112-46, 147-211), uno para chacales y leopardos, que es una adaptación del segundo de los leones (212-29), otra manera de capturar leopardos (320-53), una forma de hacerse con el oso (354-424), dos detalles sobre la persecución de liebres (425-38), una circunstancia de la persecución de las gacelas (439-47) y las dificultades de caza del zorro (448-53). Apunta S. McGrath (2020, p. 101) que, a pesar del significado del sustantivo Cynegetica, en el libro IV los perros intervienen únicamente en la caza del oso (aunque podría matizarse que también son mencionados en la caza de liebres, IV 428, y zorros, IV 452). 
Sebastián Martínez García

Los Cynegetica de pseudo-Opiano, ¿un poema incompleto?

Por otra parte, se echa de menos el relato de la caza del jabalí, teniendo en cuenta que el emperador Caracalla participaba en cacerías de dichos animales y de leones, a los que, en cambio, se dedica un extenso tratamiento. Del mismo modo, el hecho de que Caracalla se complaciese en identificarse (o la propaganda imperial en identificarlo) con Alejandro Magno y Aquiles, además de Heracles y Dioniso, hace notable la ausencia de los dos primeros en contraste con los largos excursos mitológicos sobre los dos últimos.

En suma, se debe considerar probado o altamente probable el hecho de que los Cynegetica son un poema incompleto o inacabado, y esa circunstancia ha de ser tenida en cuenta en los estudios y valoraciones de esta obra.

\section{Bibliografía}

G. Agosta, 2009, Ricerche sui Cynegetica di Oppiano, Amsterdam.

J. Aymard, 1951, Les chasses romaines des origines à la fin du siècle des Antonins, París.

A. N. Bartley, 2003, Stories from the Mountains. Stories from the Sea. The Digressions and Similes of Oppian's Halieutica and the Cynegetica, Göttingen.

A. Bartley, 2016, "The Huntress and the Poet. Artemis in the Cynegetica", en The Gods of Greek Hexameter Poetry. From the Archaic Age to Late Antiquity and Beyond, J. J. Clauss, M. Cuypers y A. Kahane (eds.), Stuttgart, pp. 243-55.

J. N. Belin de Ballu, 1786, Oppiani Poemata de Venatione et Piscatione, cum interpretatione latina et scholiis. Accessit Eutecnii paraphrasis 'I $\xi \epsilon v \tau \iota \kappa \hat{\omega} v$ et Marcelli Sidetae fragmentum de Piscibus. Tomus I. Cynegetica, Estrasburgo.

J. N. Belin de Ballu, 1787, La chasse, poëme d'Oppien, Estrasburgo.

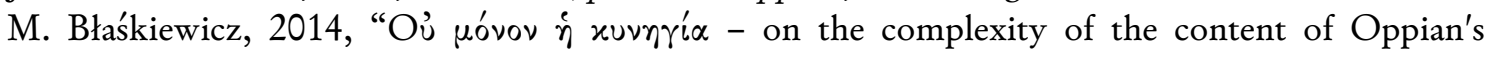
Kynegetika”, Graeco-Latina Brunensia 19-1, pp. 27-40.

J. Bodinus, 1555, Oppiani de Venatione libri IIII. Ioan. Bodino Andegavensi interprete... His accessit Commentarius, varius, et multiplex, ejusdem interpretis, París.

M. Brioso Sánchez, 1996, “Los proemios en la épica griega de época imperial”, en Las letras griegas bajo el imperio, M. Brioso y F. J. González Ponce (eds.), Sevilla, pp. 55-133.

J. Brodaeus, 1552, Annotationes in Oppiani Cynegeticon libros IIII Quinti Calabri Paralipomenon Homeri lib. XIIII. Coluthi Thebani de Helenae raptu lib. unum, Basilea.

M. Cariou, 2016, “Le topos de l'ineffable dans les catalogues poétiques”, $R P h$ 88-2, pp. 27-58.

P. Cipolla, 2009, “Nota a Opp. 'Cyn.' 382-90”, Lexis 24, pp. 517-21.

M. Detienne - J. P. Vernant, 1969, "La mètis du renard et du poulpe”, REG 82, pp. 291-317. (= Les ruses de l'intelligence. La mètis des grecs, París, 1974, pp. 32-57).

W. Dominik, 2003, "Following in whose footsteps? The epilogue to Statius' Thebaid", en Literature, Art, History: Studies on Classical Antiquity and Tradition. In Honour of W.J. Henderson, A. F. Basson y W. J. Dominik (eds.), Frankfurt am Main, pp. 91-109.

B. Effe, 1977, Dichtung und Lehre. Untersuchungen zur Typologie des antiken Lehrgedichts, Munich.

F. Fajen, 1969, Überlieferungsgeschichtliche Untersuchungen zu den Halieutika des Oppians, Meisenheim.

C. García Gual, 1971, “El prestigio del zorro”, Emerita 38, pp. 417-431.

R. K. Gibson, 2003, Ovid, Ars Amatoria Book 3, Cambridge.

H. Gossen, 1912, "Hase”, RE 7, c. 2477-2486.

P. Hamblenne, 1968, “La légende d'Oppien”, AC 37, pp. 589-619.

J. C. Iglesias Zoido, 2002, "Opiano y Virgilio: la influencia de las Geórgicas sobre la estructura de las Haliéuticas", Emerita 70, pp. 283-304.

J.-M. Jacques, 2002, Nicandre. Oeuvres. Tome II. Les Thériaques, París.

Z. Kádár, 1966, “Julia Domna comme Assyrié Kythereia et Seléné”, ACD 2, pp. 101-108.

O. Keller, 1909-1913, Die antike Tierwelt, I-II, Leipzig.

R. Keydell, 1939, “Oppianos”, RE 18-1, c. 698-708. 
E. Kneebone, 2008, “TO $\Sigma \Sigma$ ' E $\Delta \mathrm{AHN}$ : The Poetics of Knowledge in Oppian's Halieutica”, Ramus 37, 1-2, pp. 32-59.

W. Kranz, 1961, "SPHRAGIS. Ichform und Namensiegel als Eingangs- und Schlußmotiv antiker Dichtung”, RhM 104, pp. 3-46 y 97-124. (= Studien zur antiken Literatur, Heidelberg, 1967, pp. 27-78).

E. Magnelli, 2005, "Esiodo 'epico' ed Esiodo didattico: il doppio epilogo di Dionisio Periegeta", ARF 7, pp. 105-8.

A. W. Mair, 1928, Oppian. Colluthus. Tryphiodorus, Cambridge Mass.-Londres.

Th.-H. Martin, 1863, Études sur la vie et les oeuvres d'Oppien de Cilicie, París.

S. Martínez, 1995, "Els amors difícils dels animals", AFB 18, pp. 85-95.

S. Martínez, 1996, "Amor patern dels animals i pietat filial", $A F B$ 19, pp. 93-102.

S. Martínez, 2000, "Los Cynegetica fragmentarios y el fracaso del cazador”, Myrtia 15, pp. 177-85.

S. Martínez, 2003, “Opiano en la poesía bizantina: lección y leyenda”, Prometheus 29, pp. 259-68.

S. Martínez - T. Silva, 2003, "Opiano, cun poeta o dos?”, AC 72, pp. 219-30.

G. Massimilla, 1999, "Similitudini e paragoni nei Cynegetica dello pseudo-Oppiano", en Scritti in ricordo di Giacomo Bona, Potenza, pp. 193-225.

S. E. McGrath, 2020, "Cave hominem: Critical Reflections on the Treatment of Domestic Animals in Pseudo-Oppian's Cynegetica”, Mnemosyne 73, pp. 87-111.

R. A. B. Mynors, 1990, Virgil. Georgics, Oxford.

F. Orth, 1914, “Jagd", $R E$ 9-1, c. 558-604.

M. Papathomopoulos, 2003, Oppianus Apameensis Cynegetica. Eutecnius Sophistes Paraphrasis metro soluta, Munich-Leipzig.

E. Pöhlmann, 1973, “Charakteristika des römischen Lehrgedichts”, ANRW 1-3, pp. 813-901.

O. Rebmann, 1918, Die sprachlichen Neuerungen in den Kynegetika Oppians von Apamea, Basilea.

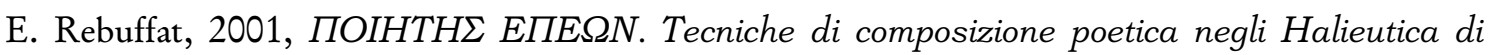
Oppiano, Florencia.

C. Rittershusius, 1597, Oppiani Poëtae Cilicis De Venatione Lib. IIII. De Piscatu Lib. V, Amsterdam.

A. M. Salvini, 1864, Oppiano. Della pesca e della caccia, Milán (primera edición en 1728).

J. G. Schneider, 1776, Oppiani poetae Cilicis de Venatione libri IV. Et de Piscatione libri V. Cum paraphrasi graeca librorum de Aucupio, Estrasburgo.

T. Silva Sánchez, 1994-1995, "Kaiserkult y creación poética. Algunas reflexiones sobre las Vitae Oppiani y la composición de los Cynegetica", ExcPhil 4-5, pp. 107-22.

T. Silva Sánchez, 1998, “Aproximación al contenido y estructura de las obras griegas sobre caza”, Actas del IX Congreso de Español de Estudios Clásicos. Literatura griega, Madrid, pp. 323-27.

T. Silva Sánchez, 2002, Sobre el texto de los Cynegetica de Opiano de Apamea, Cádiz.

T. Silva Sánchez, 2016, "Mirabilia en prosa y en verso. Sobre la poetización de contenidos paradoxográficos en la obra de los Opianos", en Fronteras entre el verso y la prosa en la literatura helenística y helenístico-romana: Homenaje al Prof. José Guillermo Montes Cala, coord. por José Guillermo Montes Cala, Rafael J. Gallé Cejudo, Manuel Sánchez Ortiz de Landaluce y Tomás Silva Sánchez, Bari, pp. 237-75.

J. M. C. Toynbee, 1973, Animals in Roman Life and Art, Londres.

K. Volk, 2002, The Poetics of Latin Didactic. Lucretius, Vergil, Ovid, Manilius, New York.

M. Wellmann, 1933, "Fuchs", RE 7-1, c. 189-92.

A. Westermann, 1845, ВІОГРАФОI. Vitarum scriptores graeci minores, Braunschweig (reimpr. Amsterdam, 1964). 